\title{
Arrhythmogenic right ventricular cardiomyopathy without arrhythmias?
}

\section{(D) Vlasta Soukup \\ Podravec*, \\ (iD) Ivana Petrović Juren, \\ (iD) Sandra Prša, \\ (D)Andreja Čleković- \\ Kovačić, \\ (DKristina Milevoj \\ Križić, \\ (iD) Renata Ivanac \\ Janković}

Bjelovar General Hospital, Bjelovar, Croatia
RECEIVED:

August 27, 2019

ACCEPTED:

September 16, 2019

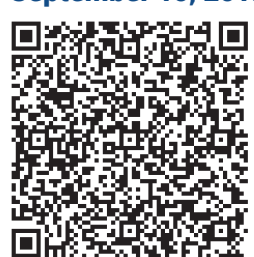

KEYWORDS: arrhythmogenic right ventricular cardiomyopathy, arrhythmias, sudden cardiac death. CITATION: Cardiol Croat. 2019;14(9-10):257-8. | https://doi.org/10.15836/ccar2019.257

*ADDRESS FOR CORRESPONDENCE: Vlasta Soukup Podravec, Opća bolnica Bjelovar, A. Mihanovića 8, HR-43000 Bjelovar, Croatia. / Phone: +385-43-279-181 / E-mail: vlasta.soukuppodravec@gmail.com

ORCID: Vlasta Soukup Podravec, https://orcid.org/0000-0002-4605-0068

Ivana Petrović Juren, https://orcid.org/0000-0002-2793-3455

Sandra Prša, https://orcid.org/0000-0001-9639-3918 • Andreja Čleković-Kovačić, https://orcid.org/0000-0002-4532-3597 Kristina Milevoj Križić, https://orcid.org/0000-0003-2115-3076 • Renata Ivanac Janković, https://orcid.org/0000-0003-4949-3953

\section{|IIIIIIIIIIIIIIIIIIIIIIIIIIIIIIIIIIIIIIIIIIIIIIIIIIIIIIIIIIIIIIIIIIIIIIIIIIIIIIIIIIIIIIIIIIIIIIIIIIIIIIIIIIIIIIIIIIIIII}

Introduction: Arrhythmogenic right ventricular cardiomyopathy (ARVC) is a rare cardiovascular disease that predisposes to ventricular arrhythmias potentially leading to sudden cardiac death (SCD). In 1994 and 2010, an International Task Force document proposed guidelines for the standardized diagnosis of ARVC based on electrocardiographic (ECG), arrhythmic, morphological, histopathologic, and clinical-genetic factors. ${ }^{1-3}$ Our case report shows how important is to diagnose this disease, because the patients with ARVC should undergo lifelong clinical follow-up to periodically evaluate new onset or worsening of symptoms, progression of morphological and/or functional ventricular abnormalities, and ventricular arrhythmias in order to reassess the risk of SCD.

Case report: 53-year-old man with history of arterial hypertension and hyperlipidemia was treated at cardiac dispensary because of bad control of blood pressure. He was asymptomatic and his family history for SCD was negative. ECG demonstrated normal sinus rhythm with complete right bundle branch block and transthoracic echocardiography (TTE) was recommended. The left ventricle had normal dimension with normal ejection fraction (EF), right ventricle was enlarged (PLAX $34 \mathrm{~mm}$ ) with bulging of apical segment RV and thickness of trabecular muscles (Figure 1). Cardiac MRI presented imaging criteria for ARVC with reduced EF RV 35\%. More detailed analysis of ECG showed epsilon wave in lead V2 (Figure 2). The 72-hours Holter electrocardiogram monitoring did not show any cardiac arrhythmias, same as during the exercise test. The patient was referred to University Clinic to make additional cardiological examinations. The ventricular late potential test was positive. Programmed stimulation of the left ventricle was made - without causing arrhythmia. The diagnosis of ARVC was confirmed one major criteria on TTE and on cardiac MRI with present epsilon wave on ECG. The risk stratification
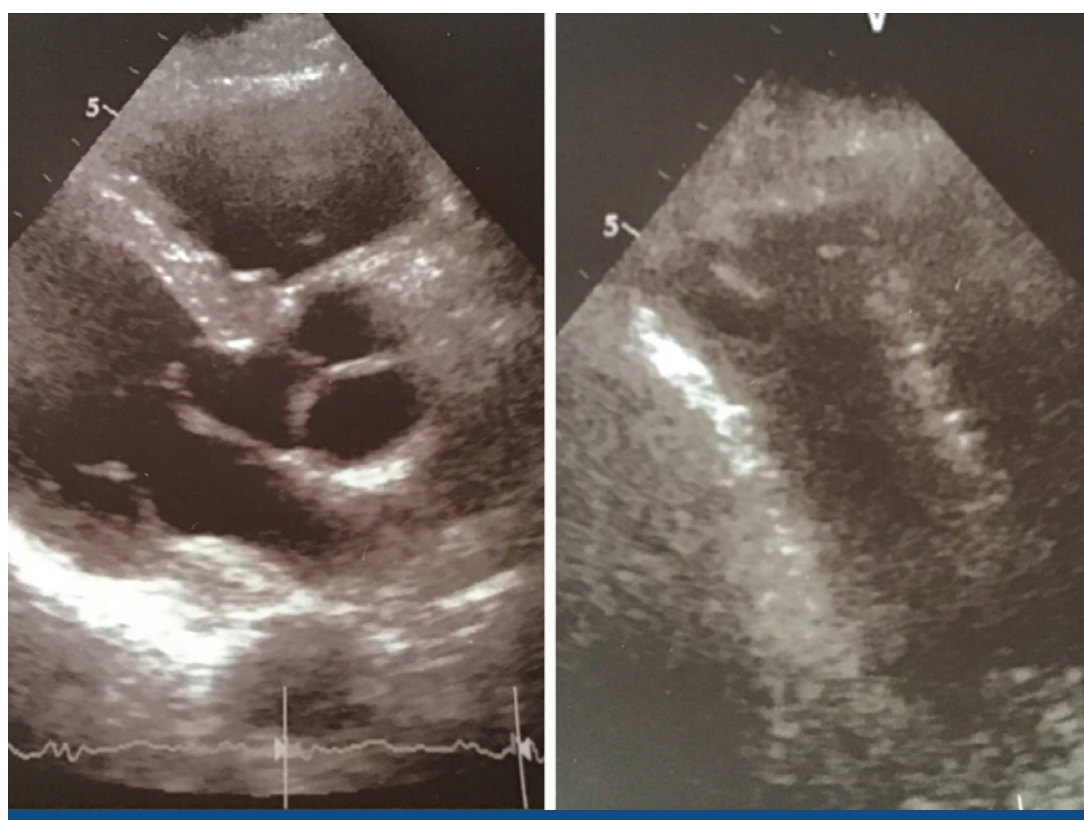

FIGURE 1. Enlargement of the right ventricle with bulging of the apical segment. 
Arrhythmogenic right ventricular cardiomyopathy without arrhythmias?

was made, the patient had low risk and the therapy with beta blocker was prescribed with limitation of physical activity and regular follow-up. Genetic testing is planned.

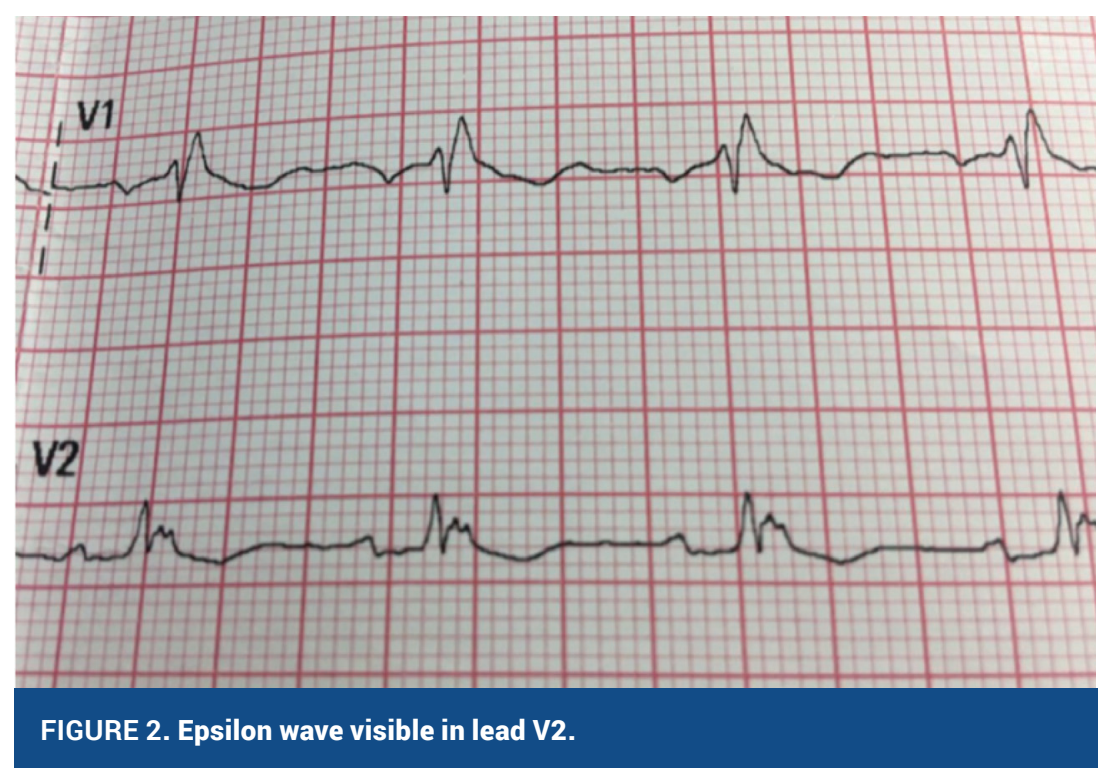

Conclusion: ARVC without arrhythmias is rare and easily misdiagnosed. The presentation can be non-specific, as was in our case, making the diagnosis of this condition challenging.

1. Marcus Fl, McKenna WJ, Sherrill D, Basso C, Bauce B, Bluemke DA, et al. Diagnosis of arrhythmogenic right ventricular cardiomyopathy/dysplasia: proposed modification of the Task Force Criteria. Eur Heart J. 2010 Apr;31(7):806-14. https://doi.org/10.1093/eurheartj/ehq025

2. Wei J, Tang J, Xia L, Chen X, Wang DW. A case of Arrhythmogenic right ventricular cardiomyopathy without arrhythmia. Diagn Pathol. 2012;7:67. https://doi.org/10.1186/1746-1596-7-67

3. Corrado D, Basso C, Thiene G. Arrhythmogenic right ventricular cardiomyopathy: diagnosis, prognosis, and treatment. Heart. 2000 May;83(5):588-95. https://doi.org/10.1136/heart.83.5.588 